\title{
Effect of Myrtus Communis L. Extracts on Attenuation of Liver Normothermic Ischemia-Reperfusion Injury
}

Henda Ferchichi', Issam Salouage ${ }^{1,2 *}$, Sarra Bacha ${ }^{1}$, Dorra Ben Said ${ }^{1}$, Emna Gaies ${ }^{1,2}$, Mohamed Boussaid $^{3}$, Mohamed Lakhal ${ }^{1}$ and Anis Klouz ${ }^{1,2}$

${ }^{1}$ Centre National de Pharmacovigilance - Tunis, Tunisia

2Unité d'Expérimentation Animale, Faculté de Médecine de Tunis, Tunisia

${ }^{3}$ Institut National des Sciences Appliquées et de Technologie INSAT, Tunisia

\begin{abstract}
The Common Myrtle (Myrtus communis L.) is rich in antioxidants, particularly in anthocyanin. It was recognized for its anti-inflammatory and anti-thrombotic effects.

The aim of our work is to evaluate the effect of Common Myrtle on a model of hepatic ischemia-reperfusion in Rat.

Two morphs were chosen: white fruit Myrtle and black fruit Myrtle. Within each morph, fruit and leaf were separated and obtained extract were used to determine their effects on the hepatic model of ischemia-reperfusion.
\end{abstract}

Our work was conducted in three steps (1) Induction of hepatic ischemia (90 minutes) in Wistar Rat (2) injection of the Myrtle extract during 15 minutes before reperfusion (3) and reperfusion ( 2 hours).

To evaluate the effect of Myrtle on ischemia-reperfusion, we have monitored transaminases levels, Monoethylglycinexylidide (MEGX) concentrations (to assess the liver metabolic capacity) and Malondialdehyde (MDA) concentration.

The determination of total phenol extracts of Myrtle showed a significant difference between black fruit Myrtle (11.3 $\mu \mathrm{g} / \mathrm{ml})$, white fruit $(27 \mu \mathrm{g} / \mathrm{ml})$ and black fruit Myrtle leaves $(94.3 \mu \mathrm{g} / \mathrm{ml})$. The latter presented the highest antioxidant activity $(86.54 \%)$.

With the extract from the white fruit of Myrtle, we noted a decrease of AST and ALT, respectively, $1321 \mathrm{U} / \mathrm{I}$ and 773 $\mathrm{U} / \mathrm{I}$ compared with I/R group was $5757 \mathrm{U} / \mathrm{I}$ and $5404 \mathrm{U} / \mathrm{I}$ and an increase in the MEGX concentrations and decrease in MDA.

The testing of extracts of Myrtle in a model of hepatic ischemia showed a difference in the protective power against damage of ischemia-reperfusion, by origin and type of fruit (black or white).

Keywords: Myrtus communis L.; Hepatic ischemia-reperfusion injury; Oxidative stress; Monoethylglycinexylidide; Lipid peroxidation; Antioxidant effect

\section{Introduction}

Myrtle (Myrtus communis, Myrtaceae) is a Mediterranean shrub used as a culinary spice and as a folk medicine, for example, in the treatment of diabetes mellitus and as an antiseptic agent. In fact, myrtle extracts have been reported to possess antihyperglycemic [1-3], and antibacterial $[4,5]$ properties. Recent reports have described antioxidant activities of different extracts of myrtle and certain ingredients thereof [6-8], implying potential as medicine for the treatment of diseases related to oxidative stress, such as warm ischemia-reperfusion (I/R).

Ischemia is a state of tissue oxygen deprivation accompanied by a reduced washout of the resulting metabolites [9]. Reperfusion is the restoration of blood flow to the ischemic tissue. Despite the unequivocal benefit of reperfusion of blood to an ischemic tissue, reperfusion itself can elicit a cascade of adverse reactions that paradoxically injure tissue [10].

Deprivation of oxygen to the liver during ischemia induces severe damage; however, much more damaging reactive oxygen species (ROS) are generated during the reperfusion period (Parks and Granger, 1988). The organ dysfunction that accompanies this condition is generally associated with increased microvascular permeability, interstitial edema, impaired vasoregulation, inflammatory cell infiltration and parenchymal cell dysfunction and necrosis $[11,12]$. Thus, surgery is well designed to prevent and manage the tissue injury associated with reperfusion.
Free radical ablation for the treatment of reperfusion injury found its first clinical application in the prevention of postischemic tissue injury after organ transplantation $[13,14]$.

Thus, free radical scavengers and antioxidant agents are thought to be useful in the clinical setting of hepatic I/R damage (KupiecWeglinski et al. 2005).

The aim of this work is to evaluate the effect of Myrtle extracts on hepatic ischemia-reperfusion in a rat model. In fact, two morphs were chosen: white and black fruit Myrtle. For each one, fruit and leaf were separated to determine their effects.

\section{Material and Methods}

\section{Chemicals}

All solvants used in this investigation were analytical grade: Folin

*Corresponding author: Issam Salouage, Unité d'Expérimentation Animale Faculté de Médecine de Tunis, Tunisia, E-mail : i.salouage@voila.fr

Received September 12, 2011; Accepted November 14, 2011; Published November 18, 2011

Citation: Ferchichi H, Salouage I, Bacha S, Said DB, Gaies E, et al. (2011) Effect of Myrtus Communis L. Extracts on Attenuation of Liver Normothermic IschemiaReperfusion Injury. J Transplant Technol Res S3:001. doi:10.4172/2161-0991.S3001

Copyright: (c) 2011 Ferchichi $\mathrm{H}$, et al. This is an open-access article distributed under the terms of the Creative Commons Attribution License, which permits unrestricted use, distribution, and reproduction in any medium, provided the original author and source are credited. 
Citation: Ferchichi H, Salouage I, Bacha S, Said DB, Gaies E, et al. (2011) Effect of Myrtus Communis L. Extracts on Attenuation of Liver Normothermic Ischemia-Reperfusion Injury. J Transplant Technol Res S3:001. doi:10.4172/2161-0991.S3-001

and Ciocalten's phenol agent: 2N, d = 1.27 (SIGMA - F9252). Methanol, acetic acid, ethyl ether and hydrogen chloride (CHEM-LAB).

Reagents used for antioxidant activity assessment were also of analytical grade: 2-thiobarbituric acid (TBA; Merck), trichloroacetic acid (TCA; Prolabo), $\mathrm{FeCl}_{3}$ (Riedel-De Haen), $\mathrm{FeCl}_{2} \cdot 4 \mathrm{H}_{2} \mathrm{O}$ (Merck) and 2,2-diphenyl-2-picrylhydrazyl free radical (DPPH) $60 \mu \mathrm{M}$ (SIGMA).

Standard solutions of Quercetin, Catechin, Kampferol and Rutin were prepared as $0.05 \%$ solutions in methanol (SIGMA).

\section{Plant material and extraction procedure}

Two morphs were chosen: white fruit Myrtle and black fruit Myrtle.

Common Myrtle has been collected in August 2007 at the locality Djebel Bargou (North West of Tunisia). The fresh plants were sorted out and dried in the drying room with active ventilation at ambient temperature. Identification was confirmed by Prof. Mohamed Boussaid (Botanic Biotechnology Department of National Institute of Applied and Technology of Tunis: INSAT)

Plant material was reduced to a fine powder and was mixed with $40 \mathrm{ml}$ of saline solution $(\mathrm{NaCl} 9 \%)$. The mixture undergoes maceration for 5 days in the refrigerator $\left(4^{\circ} \mathrm{C}\right)$. Then it was centrifuged at $4500 \mathrm{rpm}$ for $10 \mathrm{~min}$.

The extracts were sterilized through micro filters. The samples were stored in sterile tubes at $4^{\circ} \mathrm{C}$.

We obtained four extracts from black fruit of Myrtle (E I), leaves of Myrtle Black fruit (E II), white fruit of Myrtle (E III) and leaves of Myrtle White fruit (E IV).

\section{Determination of total phenolic content}

Total phenolic content was estimated by the Folin-Ciocalteu (FC) colorimetric method.

Briefly, 50 il of the plant extract was diluted 10-fold with $\mathrm{NaCl} 9 \%$ and mixed with $750 \mathrm{il}$ of FC reagent, previously diluted 10-fold with distilled water. The mixture was incubated at obscurity for $5 \mathrm{~min}$ at $37^{\circ} \mathrm{C} .750 \mathrm{il}$ of $\mathrm{Na}_{2} \mathrm{CO}_{3}(60 \mathrm{~g} / \mathrm{l})$ solution was added to the mixture. After $90 \mathrm{~min}$, the absorbance was measured at $725 \mathrm{~nm}$. A range standard was prepared in the same conditions as the samples using different concentrations of alpha tocopherol (10 to $100 \mathrm{mg} / \mathrm{ml})$.

\section{Thin-layer chromatography (TLC)}

Five grams of plant was refluxed with $100 \mathrm{ml}$ methanol for $24 \mathrm{~h}$ then filtered and $2 \mathrm{ml}$ of $\mathrm{HCl}(2 \mathrm{~N})$ was added to the filtrate, which was then heated at $100^{\circ} \mathrm{C}$ for $1 \mathrm{~h}$ until complete hydrolysis.

Acid hydrolysis of methanol extract was conducted by adding an equal volume of ethylic ether. The supernatant was concentrated under reduced pressure and then the residue was taken up in methanol.

We used Thin-layer chromatography (TLC) for flavonoid and phenolic separation.

Chromatography was carried out on silica gel using acetic acid, $\mathrm{HCl}$, water (30: 3: 10/v: v: v) as the developing solvent during $5 \mathrm{~h}$.

\section{2,2-diphenyl-1-picrylhydrazyl (DPPH) radical scavenging assay}

Due to its unpaired electron, DPPH radical gives a strong absorption band at $517 \mathrm{~nm}$ (deep violet color). As this electron becomes paired off in the presence of a free radical scavenger, the absorption vanishes and the resulting discoloration is steochiometric with respect to the number of electrons taken up. This test consist in mixing $25 \mu \mathrm{l}$ of the extract (diluted 10-fold with $\mathrm{NaCl} 9 \%$ ) with $1 \mathrm{ml}$ of 2,2-diphenyl1-picrylhydrazyl radical (DPPH) to a final concentration $0.04 \mathrm{mM}$. Mixtures were vigorously shaken and let for $30 \mathrm{~min}$ at obscurity. The control corresponds to $1 \mathrm{ml}$ of DPPH $(0.5 \mathrm{mM})$ that was diluted in $4 \mathrm{ml}$ of $\mathrm{NaCl} 9 \%$. The antioxidant activity was expressed in percentage of the inactivated DPPH radical according to the following formula [15]:

$\mathrm{DPPH}$ radical inactivation $=100 \times\left(\mathrm{A}_{0}-\mathrm{A}_{\mathrm{s}}\right) / \mathrm{A}_{0}$

$\mathrm{A}_{0}$ : absorbance of the control at $517 \mathrm{~nm}$ (containing all reagents except the test compound),

$\mathrm{A}_{\mathrm{s}}$ : absorbance of the sample at $517 \mathrm{~nm}$.

\section{Animals}

Adult male Wistar rats, weighing 250 to 350 g were provided by Tunisian Pasteur Institute and then fed in the unit of animal experimentation of the Faculty of Medicine of Tunis. All animal procedures used in this study are in strict accordance with the European Community Council Directive of 24 November 1986 (86-609/EEC) and Decree of 20 October 1987 (87-848/EEC).

Animals were subdivided in six groups ( $\mathrm{n}=5$ for each one): Sham (not treated group), I/R (normothermic ischemia-reperfusion), BMF (injection of black myrtle fruit extract), BML (injection of black myrtle leaves extract), WMF (injection of white myrtle fruit extract) and WML (injection of white myrtle leaves extract).

\section{Experimental protocol and hepatic ischemia}

For normothermic liver ischemia, the technique described by Nauta et al. [16]

The surgical procedure was performed under general Anesthesia (Urethane). After section of the ligaments of the liver, hepatic normothermic ischemia was induced for $90 \mathrm{~min}$ by hilum clamping of the hepatic pedicles of segments I to V. In order to preclude vascular congestion of the alimentary tract, the blood supply by the portal pedicles of segments VI and VII was not interrupted. During the period of ischemia $0.5 \mathrm{ml}$ of saline was given through the dorsal vein of the penis every $30 \mathrm{~min}$ to maintain hemodynamic stability and to replace losses due to portal stasis.

We injected $25 \mathrm{mg} / \mathrm{kg}$ of the extract of the Myrtle in the femoral vein 15 minutes before reperfusion [17]. Reperfusion was established by removal of the clamps.

After 120 min reperfusion, animals were killed, and the liver lobes suffering ischemic injury were immediately removed and a blood sample was collected.

\section{Biochemical assay}

Blood samples were collected for the measurement of liver enzymes (alanine aminotransferase (ALT) and aspartate aminotransferase (AST)), in order to evaluate hepatic injury.

Samples were centrifuged, then serum was separated and measurements were made by an automated analyzer (COBAS Integra 800) using the enzymatic technique EMIT (enzyme multiplied immunoassay technique).

Results were expressed in percentage (\%) of protection of AST and ALT using the following equation:

$\%$ Protection AST $=100 \mathrm{X}\left(\mathrm{AST}_{\mathrm{I} / \mathrm{R}}-\mathrm{AST}_{\text {Treated }}\right) /\left(\mathrm{AST}_{\mathrm{I} / \mathrm{R}}-\mathrm{AST}_{\text {Sham }}\right)$ 
Citation: Ferchichi H, Salouage I, Bacha S, Said DB, Gaies E, et al. (2011) Effect of Myrtus Communis L. Extracts on Attenuation of Liver Normothermic Ischemia-Reperfusion Injury. J Transplant Technol Res S3:001. doi:10.4172/2161-0991.S3-001

\section{Lipoperoxydation test}

A portion of liver (5g) was used to quantify malondialdehyde (MDA). Liver homogenate malondialdehyde (MDA) concentration was measured using the thiobarbituric acid (TBA) method. The amount of lipid peroxides (LPO) was measured as the production of MDA, which is in combination with TBA.

Briefly, mitochondrial liver $(1.25 \mathrm{mg} / \mathrm{ml})$ [18] was incubated during $10 \mathrm{~min}$ at $37^{\circ} \mathrm{C}$. Lipid peroxidation was initiated by addition of $100 \mu \mathrm{l}$ of solution of $\mathrm{FeCl}_{2} / \mathrm{FeCl}_{3}(500 / 1500 \mu \mathrm{M})$ and incubated at $37^{\circ} \mathrm{C}$ for $30 \mathrm{~min}$. Trichloroacetic acid ( $3 \% \mathrm{TCA}$ ) was added to stop the peroxidation reaction, and centrifuged at $3000 \mathrm{~g}$ for $15 \mathrm{~min}$ at $20^{\circ} \mathrm{C}$.

The supernatant was added to TBA $1 \%$, followed by incubation during $30 \mathrm{~min}$ at $95^{\circ} \mathrm{C}$. The samples were cooled, and their absorbencies were measured by spectrophotometric method at $530 \mathrm{~nm}$ using $\mathrm{NaCl}$ $0.9 \%$ and TBA $(\mathrm{v} / \mathrm{v})$ as an external standard.

$\%$ lipoperoxidation inhibition $=\left([\mathrm{MDA}]_{\mathrm{I} / \mathrm{R}}-[\mathrm{MDA}]_{\mathrm{T}}\right) /([\mathrm{MDA}]$ $\left.I_{I / R}-[\mathrm{MDA}]_{\text {Sham }}\right) \times 100$

\section{Evaluation of liver metabolic capacity: Lidocaïne test}

Two portions of $2.5 \mathrm{~g}$ of liver were used for MEGX test: a test based on the evaluation of liver metabolic capacity by the determination of Lidocaïne and MEGX concentrations. In fact, MEGX is a major metabolite of Lidocaine which is exclusively metabolized in the liver by the cytochrome P450 [18].

Same equation was used to determine the percentage of protection of ALT and MEGX.

\section{Statical analysis}

All values are given as means \pm S.E.M. Statistical comparisons were made by using ANOVA test. A p value $<0.05$ was considered statistically significant.

\section{Results}

\section{Polyphenol}

The total phenols determined by the Folin-Ciocalteu method for the four aqueous extracts of Myrtle (Extracts: EI, EII, EIII and EIV) varied from $103.2 \mu \mathrm{g} / \mathrm{ml}$ for the leaves of Myrtle Black fruit (EII) to 11.3 $\mu \mathrm{g} / \mathrm{ml}$ for black fruit of Myrtle (EI).

The total phenolic compound contents in the plant extracts are shown in table 1.

\section{TLC separation}

TLC (methanolic extracts of Myrtle) indicated the presence of 7 compounds for black fruits of Myrtle, 8 compounds for leaves of Myrtle white fruit and Myrtle black fruit and for white fruit of myrtle.

We identified four compounds: Quercitrin $(\mathrm{RF}=0.47)$, Catechin $(\mathrm{RF}=0.6)$, Kampferol $(\mathrm{RF}=0.68)$ and Rutin $(\mathrm{RF}=0.78)$.

Only samples of leaves from both morph (EII and EIV) contained Catechin. Quercitin, Kampferol and Rutin exist in all extracts (EI, EII, EIII and EIV). (Figure 1)

\section{DPPH}

In order to evaluate the antioxidant capacity of the samples, a method based on the reduction of DPPH was performed. DPPH radical is one of the few stable organic nitrogen free radicals, which has been widely used to determine the free radical-scavenging ability of various samples. Results of DPPH reduction by the 4 extracts are shown in table 1.

Quantitative analysis revealed that the leaves of Myrtle (black and white fruit) (EI and EIV) extracts showed the strongest DPPH radical scavenging property ( $86.5 \%$ and $90.7 \%$ respectively). The other extracts (EII and EIII) present a low antioxidant activity $(35.1 \%$ and $21.2 \%$ respectively).

\section{Lipoperoxydation test}

The MDA content as an index of lipid peroxidation was significantly higher after reperfusion in I/R group $(6.4 \pm 1.1 \mu \mathrm{M})$ than in sham group $(1.4 \pm 0.4 \mu \mathrm{M})$.

For BML group, MDA decreased significantly $2.6 \pm 0.6 \mu \mathrm{M}(\mathrm{p}<$ 0.05) compared with I/R group.

\section{Serum transaminases levels}

The ALT and AST serum levels of the sham group were $153 \pm 27$ $\mathrm{U} / \mathrm{l}$ and $74 \pm 18 \mathrm{U} / \mathrm{l}$ respectively. Serum ALT and AST levels increased significantly after reperfusion in I/R group compared with sham group (5757 $\pm 383 \mathrm{U} / \mathrm{l}$ and $5404 \pm 1453 \mathrm{U} / \mathrm{l}$ respectively).

Pretreatment with Myrtle significantly decreased AST and ALT levels compared with I/R group.

With BML group, we noted a significant decrease of AST and ALT, respectively, $1537 \pm 197 \mathrm{U} / \mathrm{I}$ and $1007 \pm 182 \mathrm{U} / \mathrm{I}$ compared with the I/R group $(\mathrm{p}=0.03<0.05)$.

For WML group, Rats died few minutes after injection of the extract (Table 2).

\section{Monitoring of MEGX formed}

This test evaluates the metabolic capacity of liver. The concentration of the formed MEGX reached $660 \pm 44 \mu \mathrm{M}$ in the sham group and decreased significantly to $81 \pm 13 \mu \mathrm{M}$ for the I/R group.

This concentration increased, after injection of myrtle extracts, to reach values of $222 \pm 48 \mu \mathrm{M}, 177 \pm 32 \mu \mathrm{M}$ and $275 \pm 39 \mu \mathrm{M}$ for BMF, $\mathrm{BML}$ and WMF groups respectively.

The differences between treated groups and I/R group are

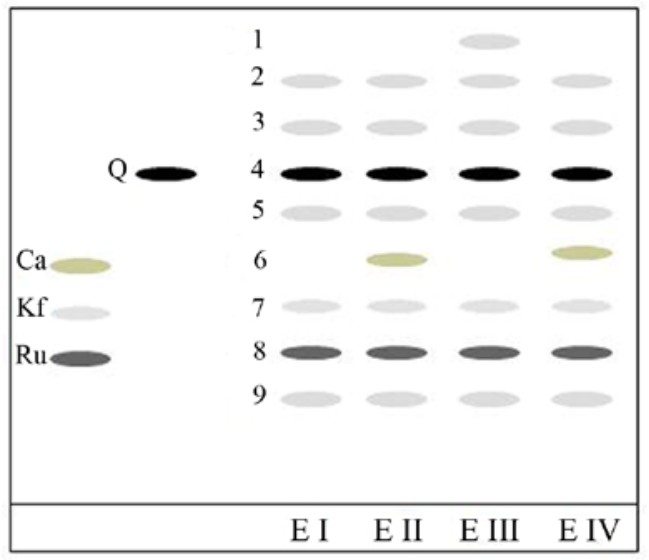

Key to the spots: $\mathrm{Ca}$ - catechin, $\mathrm{Q}$ - quercetin, $\mathrm{Kf}$ - kampferol, Ru - rutin Figure 1: Schematic TLC separation on silica gel, with acetic acid, $\mathrm{HCl}$, water (30: $3: 10 / v: v: v)$ as the mobile phase, of flavonoids and phenolic acids (1-9) in leaves and fruits of Commun Myrtle. 
Citation: Ferchichi H, Salouage I, Bacha S, Said DB, Gaies E, et al. (2011) Effect of Myrtus Communis L. Extracts on Attenuation of Liver Normothermic Ischemia-Reperfusion Injury. J Transplant Technol Res S3:001. doi:10.4172/2161-0991.S3-001

significant with probabilities lower than 0.05. (Table 2).

For WML group, Rats died few minutes after injection of the extract.

\section{Discussion}

Many vegetal extracts show an important antioxidant activity that is linked to the presence of phenols compounds. The antioxidant activity of Myrtle (Myrtus communis L.) extract from different materials has been studied in animal models, so this activity depends on phenolic compounds concentrations and their natures in plant extracts [8].

\section{Antioxidant activity of Myrtle}

In the first part of this study, we focused our attention on the identification (Thin-layer chromatography) and the quantification (total phenols concentration) of the Myrtle phenols and testing their antioxidant activity (DPPH).

The extracts of leaves of Myrtle (Black and White) showed a higher polyphenol concentration and may be rich sources of antioxidants compounds. Meeker et al. found that the activity of phenolic compounds is indeed conditioned by their chemical composition [19].

The difference in the composition in polyphenols may explain the difference in the antioxidant action (DPPH inhibition), obtained by each Myrtle extract (fruit and leaves of the white and black morph).

Previous studies have shown that phenols have antioxydant activities, which contribute to the explanation of the protective effect of plants against some diseases [20].

The capacity of extracts of Myrtle to scavenger free radicals can be attributed to flavonoïdes and phenolic acids [8]. The variation of the antioxydant activity of Myrtle extracts according to the morphs (black or white) and according to organs (fruits or leaves), can be explained by a difference in the flavonoïdes composition revealed by TLC in one hand, and by a difference in total phenols content on the other hand. Thus, the most important quantity of total phenols was detected in extract of leaves of Myrtle Black fruit.

\section{Liver ischemia-reperfusion}

The second part of this study, we aimed to find solutions to protect liver against lesions induced by I/R, specially the oxidant generation using vegetal extracts.

$\mathrm{I} / \mathrm{R}$ injury of the liver is a major complication of liver resection, hepatic trauma, and liver transplantation. During the last two decade, a significant progress has been made in understanding liver ischemiareperfusion injury and in the development of strategies to avoid or reduce this injury in clinical practice. [21].

Reactive oxygen species have been implicated in the pathogenesis of ischemia/reperfusion injury.

The oxidative stress during reperfusion after hepatic ischemia has been reported by assessing MDA [22].

Liver Malondialdehyde levels, a marker of oxidative stress, permitted us to obtain a quantitative estimation of the membrane lipid oxidative damage (Esterbauer et al. 1990).

In the present study, I/R caused significant increases in the hepatic malondialdehyde levels, end products of lipid peroxidation. This observation is in agreement with the previous studies, where elevated levels of lipid peroxidation products were increased from $40 \%$ to 80 above basal values [23-25]. Furthermore, our results demonstrated that leaves of Myrtle Black fruit treatment can inhibit the production of oxygen radicals and prevent them from injury to liver tissue.

A major target site of lipid peroxidation damage is the cellular membrane because it contains polyunsaturated fatty acids. Toxicity of partially reduced oxygen species arises from the peroxidation of polyunsaturated fatty acid of membrane phospholipids, which may cause membrane disintegration. In liver ischemia-reperfusion injury, this mechanism is exacerbated. The consequent damage to liver cells by reperfusion results in mitochondrial dysfunction and it can also induce enzymes release.

Devinder et al. [26] showed, in their study, that oxidative stress induced by $\mathrm{I} / \mathrm{R}$ was associated with enzymatic liver increase in plasma (transaminase).

Transaminase levels (AST and ALT) are considered as excellent markers of hepatocellular injury and a good indicator of structural membrane damage [27]. Thus, this assay allows us to test the ability of these plant extracts to protect the liver against the deleterious effects of ischemia [28].

\begin{tabular}{|l|l|l|}
\hline & Total phenols $(\boldsymbol{\mu g} / \mathbf{m l})$ & $\%$ of $\mathbf{D P P H}$ inhibition \\
\hline EI & 11.3 & 35.1 \\
\hline EII & 103.2 & 86.5 \\
\hline EIII & 27 & 21.2 \\
\hline EIV & 94.3 & 90.7 \\
\hline
\end{tabular}

El: extract of the black fruit of Myrtle, Ell: extract of leaves of Myrtle Black fruit, EIII: extract of the white fruit of Myrtle, EIV: extract of leaves of Myrtle White fruit

Table 1: Dosage of total phenols and \% of DPPH inhibition of each Myrlte extracts.

\begin{tabular}{|l|l|l|l|l|}
\hline \multirow{5}{*}{} & \multicolumn{3}{l}{ Biochemical parameter } \\
\cline { 2 - 5 } & AST $(\mathrm{U} / \mathrm{l})$ & ALT $(\mathrm{U} / \mathrm{l})$ & MEGX $(\mu \mathrm{M})$ & MDA $(\mu \mathrm{M})$ \\
\hline Sham & $153 \pm 27$ & $74 \pm 18$ & $660 \pm 44$ & $1.4 \pm 0.4$ \\
\hline I/R & $5757 \pm 383^{\mathrm{a}}$ & $5404 \pm 1453^{\mathrm{a}}$ & $81 \pm 13^{\mathrm{a}}$ & $6.4 \pm 1.1^{\mathrm{a}}$ \\
\hline BMF & $4610 \pm 237^{\mathrm{b}}$ & $4584 \pm 318$ & $222 \pm 48^{\mathrm{b}}$ & $5.5 \pm 1.4$ \\
\hline BML & $1537 \pm 197^{\mathrm{b}}$ & $1007 \pm 182^{\mathrm{b}}$ & $177 \pm 32^{\mathrm{b}}$ & $2.6 \pm 0.6^{\mathrm{b}}$ \\
\hline WMF & $1321 \pm 610^{\mathrm{b}}$ & $773 \pm 558^{\mathrm{b}}$ & $275 \pm 39^{\mathrm{b}}$ & $5.2 \pm 1$ \\
\hline WML & - & - & - & - \\
\hline
\end{tabular}

Values are expressed as mean \pm standard deviation of five rats at $p<$ 0.05. Alanine Aminotransferase (ALT), Aspartate Aminotransferase (AST) Monoethylglycinexylidide (MEGX) and malondialdehyde (MDA)

aSignificantly different from sham versus $\mathrm{I} / \mathrm{R}$ group at $p<0.05$

bSignificantly different from $I / R$ versus treated groups at $p<0.05$

Sham (non treated group), I/R (normothermic ischemia-reperfusion), BMF group (injection of black myrtle fruit extract), BML group (injection of black myrtle leaves extract), WMF group (injection of white myrtle fruit extract) and WML group (injection of white myrtle leaves extract)

For WML group Rats died few minutes after injection of the extract

Table 2: Effect of each extracts of Commun Myrtle on the biochemical parameters in rat ischemia-reperfusion liver.

\begin{tabular}{|l|l|l|l|l|}
\hline & $\begin{array}{l}\% \text { of } A S T \\
\text { protection }\end{array}$ & $\begin{array}{l}\% \text { of ALT } \\
\text { protection }\end{array}$ & $\begin{array}{l}\% \text { of MEGX } \\
\text { protection }\end{array}$ & $\begin{array}{l}\% \text { of inhibition of } \\
\text { lipoperoxidation }\end{array}$ \\
\hline BMF & $21 \pm 4.2$ & $15 \pm 6$ & $24 \pm 8$ & $19 \pm 0.3$ \\
\hline BML & $75 \pm 4$ & $83 \pm 3.4$ & $17 \pm 6$ & $77 \pm 1.8$ \\
\hline WMF & $79 \pm 11$ & $87 \pm 11$ & $34 \pm 7$ & $24 \pm 1.2$ \\
\hline WML & - & - & - & - \\
\hline
\end{tabular}

Values are expressed as mean \pm standard deviation of five rats at $p<0.05$ Aminotransferase (ALT), Aspartate Aminotransferase (AST) and Monoethylglycinexylidide (MEGX)

BMF group (injection of black myrtle fruit extract), BML group (injection of black myrtle leaves extract), WMF group (injection of white myrtle fruit extract) and WML group (injection of white myrtle leaves extract)

Table 3: Effect of each myrtle extract on AST and ALT blood levels, on liver metabolic function (MEGX test) and lipoperoxidation in different groups of rats. 
Citation: Ferchichi H, Salouage I, Bacha S, Said DB, Gaies E, et al. (2011) Effect of Myrtus Communis L. Extracts on Attenuation of Liver Normothermic Ischemia-Reperfusion Injury. J Transplant Technol Res S3:001. doi:10.4172/2161-0991.S3-001

Page 5 of 6

The heterogenic phenols composition can explain the difference of anti ischemic effects obtained by every aqueous extracts of Myrtle.

The white Myrtle fruit extract presents the most important protection transaminase rate although low ployphenols quantity and low antioxidant effect.

According to the literature, the rate of liver protection against reperfusion period depends of the relationship with his protective antioxidant capacity [29]. This leads us to believe that there is other compound, other that phenols, which can be responsible for antiischemic action, present in the Myrtle extract.

The reduction of transaminase rate is the lowest observed in the extract of fruits of the black Myrtle (Table 3).

Myrtle extracts improved metabolic function which was evaluated by liver capacity to transform Lidocaine into MEGX and other metabolites. This test has been used in several studies as a quantitative index of hepatic functions [30]. It has been reported that the hepatic metabolism of Lidocaïne to Monoethylglycinexylidide (MEGX) is the basis of dynamic tests of liver function and that it is more discriminatory and recognizes early damage to the liver than conventional individual liver function tests and it shows a good correlation with severity of liver injuries [31-33].

Among all plant extracts used, we obtained a best protection of MEGX rate formation for the white fruit of Myrtle extract (Table 3).

In most cases, the injection of extract of leaves Myrtle white fruit causes cardiac arrest few minutes after injection. In fact, the Myrtle has a proved hypotensive effect [34,35].

Otherwise, flavonoids have attracted great attention in the prevention and treatment of hypertensive disease and it can reduce the risk of artery disease [36,37].

Indeed, catechin has anti-hypertensive proprieties [38]. According to results by TLC, only samples of leaves from both morph (EII and EIV) contained Catechin. We suppose that catechin concentration is very important for the EIV extract.

In summary, in the present study, we found that hepatic I/R caused a significant increase in the serum levels of AST and ALT which reflected the degree of liver injury in association with increased MDA contents and decrease MEGX concentrations in liver tissues. Pretreatment with Myrtle extracts (EI, EII and EIII) could reduce MDA contents and elevate MEGX concentrations in liver tissues, which are associated with the attenuation of liver injury.

But we noted a difference in the protective power against damage of ischemia-reperfusion, by origin and type of fruit (black or white).

The results confirmed that leaves of Myrtle Black fruit has an important protective effects against I/R injury, which may be partly due to its antioxidative effects.

Also, the addition of the white fruit of Myrtle extract permitted us to avoid deleterious effects of ischemia-reperfusion despite this low antioxidant activity.

It possible to use leaves Myrtle white fruit for therapeutic application of the hypotensive effect.

Chemical elucidation of the extracts contents should be the main objective of further investigations. This should lead to the structural identification of the active metabolites and the determination of their antioxidant profile in pure form.

\section{References}

1. Elfellah MS, Akhter MH, Khan MT (1984) Anti-hyperglycaemic effect of an extract of Myrtus communis in streptozotocin-induced diabetes in mice. Journa of Ethnopharmacol 11: 275-281

2. Sepici A, Gurbuz I, Cevik C, Yesilada E (2004) Hypoglycaemic effects of myrtle oil in normal and alloxan-diabetic rabbits. J Ethnopharmacol 93: 311-318.

3. Onal S, Timur S, Okutucu B, Zinnioglu F (2005) Inhibition of alpha-glucosidase by aqueous extracts of some potent antidiabetic medicinal herbs. Prep Biochem Biotechnol 35: 29-36.

4. Al-Saimary IE, Bakr SS, Jaffar T, Al-Saimary AE, Salim H, et al. (2002) Effects of some plant extracts and antibiotics on Pseudomonas aeruginosa isolated from various burn cases. Saudi Med J 23: 802-805.

5. Bonjar GH (2004) Antibacterial screening of plants used in Iranian folkloric medicine. Fitoterapia 75: 231-235.

6. Rosa A, Deiana M, Casu V, Corona G, Appendino G, et al. (2003) Antioxidant activity of oligomeric acylphloroglucinols from Myrtus communis $L$. Free Radic Res 37: 1013-1019.

7. Hayder N, Abdelwahed A, Kilani S, Ammar RB, Mahmoud A, et al. (2004) Antigenotoxic and free-radical scavenging activities of extracts from (Tunisian) Myrtus communis. Mutat Res 564: 89-95.

8. Romani A, Coinu R, Carta S, Pinelli P, Galardi C, et al. (2004) Evaluation of antioxidant effect of different extracts of Myrtus communis L. Free Radic Res 38: $97-103$.

9. Star RA (1998) Treatment of acute renal failure. Kidney Int 54: 1817-1831

10. Bonventre JV (1993) Mechanisms of ischemic acute renal failure. Kidney Int 43: $1160-1178$

11. Werns SW, Lucchesi BR (1990) Free radical and ischemic tissue injury. Trends Pharmacol Sci 11: 161-166.

12. Granger DN, Korthuis RJ (1995) Physiological mechanisms of postischemic tissue injury. Ann Rev Physiol 57: 311-332.

13. Amersi F, Nelson SK, Shen XD, Kato H, Melinek J, et al. (2002) Bucillamine, a thiol antioxidant, prevents transplantation-associated reperfusion injury. Proc Natl Acad Sci USA 99: 8915-8920.

14. Seo MY, Lee SM (2002) Protective effect of low dose of ascorbic acid on hepatobiliary function in hepatic ischemia/reperfusion in rats. J Hepatol 36: 72-77.

15. Kukić J, Popovic V, Petrovic S, Mucaji P, Stojvic D, et al. (2007) Antioxidant and antimicrobial activity of Cynara cardunculus extracts. Food Chemistry 107 861-868.

16. Nauta RJ, Uribe M, Walsh DB, Miller D, Butterfield A (1989) Description of a chronic in vivo model for the study of warm hepatic ischaemia-reperfusion injury. Surg Res Commun 6 : 241-246

17. De Paola R, Muià C, Mazzon E, Genovese T, Crisafulli C, et al. (2005) Effects of hypericum perforatum extract in a rat model of ischemia and reperfusion injury. Shock 24: 255-263.

18. Klouz Anis, Ben Saïd Dorra, Ferchichi Henda, Kourda Nadia, Ouanes Lobna, et al. (2008) Protection of cellular and mitochondrial functions against liver ischemia by N-benzyl-N'-(2-hydroxy-3,4-dimethoxybenzyl)-piperazine (BHDP), a sigma1 ligand. Eur J Pharmacolo 578: 292-299.

19. Meeker HC, Schuller GL, Fusco F, Giardina-Becket MA, Sersen E, et al. (1990) Sequential monitoring of leprosy patients with serum antibody levels to phenolic glycolipid I, a synthetic analog of phenolic glycolipid I and mycobacterial lipoarabinomanan. Intern J Leprosy Mycobact Dis 58: 503 - 511.

20. Montoro P, Braca A, Pizza C, De Tommasi N (2005) Structure antioxidan activity relationships of flavonoids isolated from different plant species. Food Chem 92: 349-355

21. Kanoria S, Glantzounis G, Jalan R, Davies NA, Seifalian AM, et al. (2004) A model to study total hepatic ischemia-reperfusion injury. Transplantation proceedings 36: $2586-2589$.

22. Grattagliano, Vendemiale G, Errico F, Bolognino AE, Lillo F, et al. (1999) Chronic ethanol intake induces oxidative alterations in rat testis. J Appl Toxico 17: 307-311.

23. Sener G, Tosun O, Sehirli AO, Kaçmaz A, Arbak S, et al. (2003) Melatonin 
Citation: Ferchichi H, Salouage I, Bacha S, Said DB, Gaies E, et al. (2011) Effect of Myrtus Communis L. Extracts on Attenuation of Liver Normothermic Ischemia-Reperfusion Injury. J Transplant Technol Res S3:001. doi:10.4172/2161-0991.S3-001

and $\mathrm{N}$-acetylcysteine have beneficial effects during hepatic ischemia and reperfusion. Life Sci 72: 2707-2718.

24. Ofluoglu E, Kerem M, Pasaoglu H, Turkozkan N, Seven I, et al. (2006) Delayed energyprotection of ischemic preconditioning on hepatic ischemia/reperfusion injury in rats. Eur Surg Res 38: 114-121.

25. Zhu WH, Leng XS, Zhu JY (2006) Effect of Shenfu injection on ischemiareperfusion injury of rat liver graft. Hepatobiliary Pancreat Dis Int 5: 205-209.

26. Devinder Singh, Chopra K (2004) Effect of trimetazidine on renal Ischemia/ Reperfusion injury in rats. Pharmacol Res 50: 623-629.

27. Limdi JK, Hyde GM (2003) Evaluation of abnormal liver function tests. Postgrad Med J 79: 307-312.

28. Kundrotas LW, Clement DJ (1993) Serum alanine aminotransferase (ALT) elevation in symptomatic US Air Force basic trainee blood donors. Digest Dis Sci 38: 45-50.

29. Alamanni MC, et Cossu M (2007) Radical scavaging activity and antioxidan activity of liquors of Myrtle (Myrtus Communis L.) berries and leaves. Ital J Food Science 16: 197-208

30. Oellerich M, Amstrong VW (2001) The MEGX test: a tool for the real-time assessment of hepatic function. Ther Drug Monit 23: 81-92.

31. Huang YS, LS, Deng JF, Wu JC, Lu RH, et al. (1993) Measuring lidocaine metabolite monoethyl glycinexylidide as a quantitative index of hepatic function in adults with chronic hepatitis and cirrhosis. J Hepathology 19: 140-147.

32. Testa R, Risso D, Arzani L, Campo N, Alvarez S, et al. (1997)
Monoethylglycinexylidide formation measurement as a hepatic function test to assess severity of chronic liver disease. Am J Gastroenterol 92: 2268-2273.

33. Dresing K, Leip CL, Streit F, Burchardi H, Stürmer KM, et al. (2007) Real-time assessment of hepatic function is related to clinical outcome in critically ill patients after polytrauma. Clin Biochem 40: 1194-2200.

34. Bruneton J (1999) Pharmacognosie, Phytochimie, Plantes médicinales. 3e Edition, Tec \& Doc. Lavoisier, Paris.

35. Eddouks M, Khalidi A, Zeggwagh NA (2009) Approche pharmacologique des plantes utilisées traditionnellement dans le traitement de l'hypertension artérielle au Maroc. Phytothérapie 7: 122-127.

36. Hertog MG, Feskens EJ, Hollman PC, Katan MB, Kromhout D (1993) Dietary antioxidant flavonoids and risk of coronary heart disease: the Zutphen Elderly Study. Lancet 342: 1007-1011.

37. Renaud S, de Lorgeril M (1992) Wine, alcohol, platelets, and the French paradox for coronary heart disease. Lancet 339: 1523-1526.

38. Jaffri JM, Mohamed S, Rohimi N, Ahmad IN, Noordin MM, et al. (2011) Antihypertensive and cardiovascular effects of catechin-rich oil palm (Elaeis guineensis) leaf extract in nitric oxide-deficient rats. J Med Food 14: 775-783.

39. Katalini V, Milos M, Kulisic T, Jukic M (2006) Screening of 70 medicinal plan extracts for antioxydant capacity and total phenols. Food chemistry 94: 550557

40. Loziene K, Venskutonis PR, Sipailiene A, Labokas J (2007) Radical scavanging and antibactirial properties of the extracts from differents Thymus pulegioides L. Chémotypes. Food chemistry 103: 546-559.
This article was originally published in a special issue, Ischemia - Reperfusion Injury handled by Editor(s). Dr. Manuel Maglione, Innsbruck Medica University, Austria; Dr. Pankaj Saxena, University of Western Australia, Australia 